\title{
Waterpipe smoking: a review of pulmonary and health effects
}

\author{
Fares Darawshy (i), Ayman Abu Rmeileh, Rottem Kuint and Neville Berkman
}

Institute of Pulmonary Medicine, Hadassah-Hebrew University Medical Center, Jerusalem, Israel.

Corresponding author: Fares Darawshy (Fares@hadassah.org.il)

Check for
updates

Shareable abstract (@ERSpublications)

Waterpipe smoking is increasing in popularity worldwide despite its deleterious cardiac and respiratory health effects and associated increased risk of malignancy. There is a need to identify waterpipe smokers, educate them and encourage smoking cessation. https://bit.ly/2YB7K0j

Cite this article as: Darawshy F, Abu Rmeileh A, Kuint R, et al. Waterpipe smoking: a review of pulmonary and health effects. Eur Respir Rev 2021; 30: 200374 [DOI: 10.1183/16000617.0374-2020].

\section{Abstract}

Waterpipe smoking is an old form of tobacco smoking, originating in Persia and the Middle East. The popularity of the waterpipe is increasing worldwide, particularly among young adults, and there are widespread misconceptions regarding its negative health effects. The inhaled smoke of the waterpipe contain several toxic and hazardous materials including nicotine, tar, polyaromatic hydrocarbons and heavy metals, all of which are proven to be related to lung diseases and cancer. Regular waterpipe smoking is associated with respiratory symptoms, a decrease in pulmonary function and increased risk for lung disease such as COPD. Additional negative health effects include increased risk for arterial stiffness, ischaemic heart disease and several cancer types including lung cancer. This review summarises the negative health effects of waterpipe smoking, with emphasis on cardiorespiratory complications. Increased awareness and knowledge amongst healthcare professionals will hopefully help identify waterpipe smokers and promote patient education. Applying World Health Organization (WHO) regulations will provide a synergistic effect in reducing waterpipe use and associated disease.

\section{Introduction}

Water pipe smoking (WPS) is a form of tobacco use that has been practiced for several centuries, and has recently gained enormous popularity. In Middle Eastern and southern Asian countries, WPS has long been a traditional means of inhaling tobacco. While cigarette use has declined in the last few years in Western countries, the use of other tobacco products such as WPS has risen dramatically over the last two decades $[1,2]$. In North America and Europe, WPS is usually practiced in cafes or bars that can be found in most of the major cities.

Waterpipe smoking is mistakenly perceived as safer than smoking cigarettes. In addition, the lack of a good quality data on the adverse effects of WPS also contributes to public misconception. In this review, we describe the epidemiology and general health effects of WPS with an emphasis on cardiac and respiratory effects.

\section{History and modern use of waterpipes}

The waterpipe has several names, including hookah, narghile, argila, nafas, goza and shisha [3, 4]. The waterpipe is believed to have originated in Persia when two Persian princes declared a contest for the most entertaining invention. Through several centuries, the waterpipe travelled to the Middle East, Arab countries and Turkey and became a very popular form of smoking.

The traditional waterpipe is composed of several components (figure 1) [4, 5]. The head/bowl is usually filled with different forms of tobacco that can be found in several flavours and sweetened with artificial sweeteners or honey. The most common form of the tobacco is "Moassel", which is made in Arab countries such as Egypt and Bahrain [6]. Another form is the "Ajami”, a pure tobacco paste. Charcoals are added to the tobacco either directly or after covering it with a perforated sheet of aluminium foil. The body 


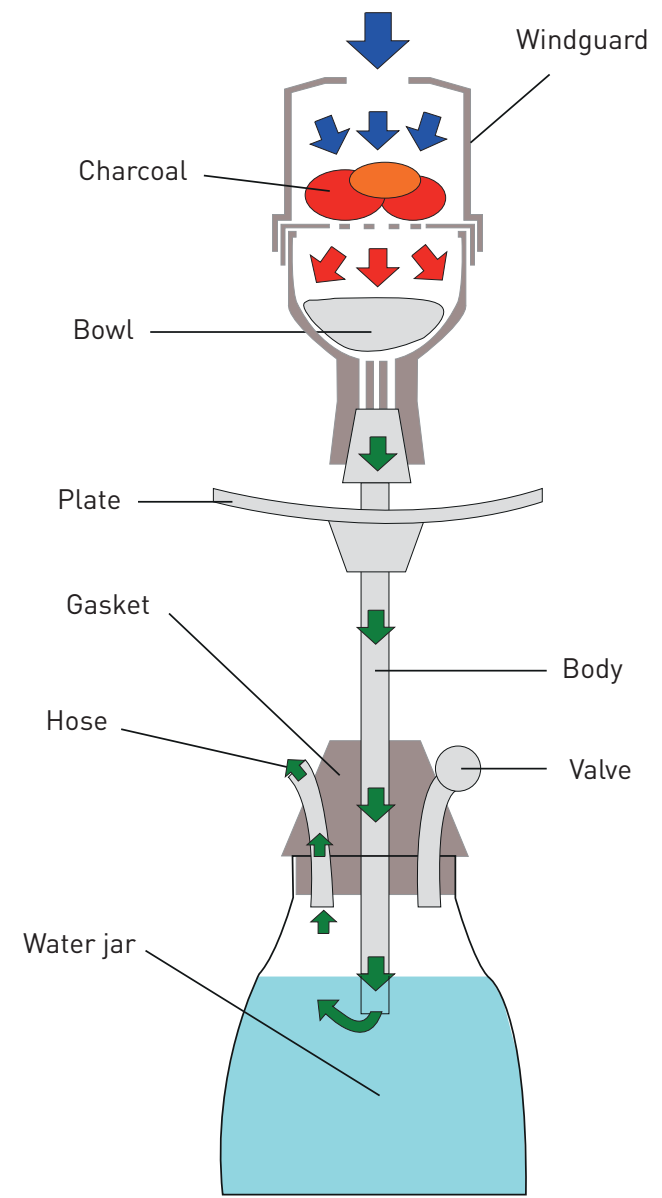

FIGURE 1 Illustration of the waterpipe and its parts. Reproduced with permission from Wikimedia commons: https://commons.wikimedia.org/wiki/File:Hookah-lookthrough.svg.

is a metal pipe that connects the bowl with the base. The base is partially filled with water and has two ports: one used as a valve and the other attaches to a hose through which the user inhales the smoke.

The active burning of the tobacco by the charcoals produces smoke that is inhaled through the hose. As the user inhales, a vacuum is created in the base, which sucks the smoke down from the head. This action creates bubbles inside the water. The smoking sessions vary in time and can last for $0.5-1.5$ hours. The volume of smoke inhaled during a single session of waterpipe smoking is $50-100$ times the smoke inhaled from a single cigarette [7].

\section{Epidemiology}

Waterpipe smoking is becoming a worldwide social phenomenon, practiced by individuals or in group settings such as cafes or bars. While the use of cigarettes has declined in the last few decades, the use of noncigarette tobacco products has increased [2], including waterpipe smoking.

Few countries have conducted systematic epidemiological surveys to ascertain the prevalence of waterpipe smoking [8], thus, the exact prevalence of this habit is largely unknown. In countries where data was collected, the trends were concerning, and showed an increase in popularity among adolescents. For example, a survey performed among 13-15 year olds, in the Middle East, showed that regular WPS in this age group was as high as 9-15\% [9]. In the Middle East, WPS has replaced cigarettes as the most popular method of tobacco use among young adults and adolescents and, in several other parts of the world, it has become second only to cigarettes [10]. In a recent systematic review, data showed marked regional variation in the prevalence of waterpipe smoking [11]. Overall, prevalence seems to be increasing with a reported prevalence of $20-70 \%$ in Mediterranean regions [12], 34.2\% in Lebanon, 32.9\% in the West Bank, 8.9\% in Canada [13] and 9.8\% in the USA [1]. Higher prevalence rates of $30-35 \%$ were also seen 
in other parts of the world, i.e. Vietnam, Ukraine and Russia [14]. In the United Kingdom, WPS was reported in $11.6 \%$ of adults in 2012 , and $12 \%$ of secondary school students. Another study conducted in the UK showed waterpipe smoking to be more than twice as prevalent as cigarette smoking (7.6\% versus 3.4\%) in a sample of 2399 students [15]. A study from Israel, showed WPS rates of 37\% in Israeli Arab high school students [16]. In the BREATHE COPD study [17], an international study that estimated the regional prevalence of COPD in the Middle East and North Africa, 3.5\% of people diagnosed with the disease reported waterpipe use, with the highest rate of users from Lebanon and Saudi Arabia. In addition, studies demonstrated a wide variation in prevalence of WPS among different populations. In a cross-sectional analysis of the global adult tobacco survey, prevalence of waterpipe smoking was low in low and middle income countries as India, Russia and Egypt, but higher among concurrent cigarette smokers [18].

Variation in prevalence rates can be attributed to different methods and definitions among studies. To overcome the variation in prevalence rates, initiatives such as the Global Tobacco Surveillance System (GTSS) were introduced to standardise tobacco use surveillance. The GTSS data showed a variance in WPS prevalence according to region, age and sex [19]. According to this dataset, and although regional variations exist, WPS seems to be highest among male Arab youths in the Middle East, compared with adults in this region or with its prevalence in Europe or in America.

The pattern of waterpipe use is another important consideration. Studies show that WPS is usually intermittent and not performed on a daily basis [9, 20]. This is best described in the study of WARD et al. [20] which showed that among a sample of 18-65 year old adults, most cigarette smokers were daily smokers, while most waterpipe smokers were intermittent smokers. In addition, many people who smoke regularly use more than one type of tobacco; this is true in high school students and in young adults [21]. Bou FAKHREDDINE et al. [4] demonstrated that waterpipe smokers are twice as likely to become cigarette smokers in the coming years. CASE et al. [22] showed that waterpipe smoking is a risk factor for other forms of tobacco consumption, including electronic cigarettes.

Several factors may lead to the popularity of waterpipe smoking, particularly among young adults. First, the introduction of flavoured waterpipe tobacco, such as sweet, exotic or fruity flavours or natural additives such as sugar cane or honey, make this form of consumption more appealing. Second, although SIDANI et al. [23] found no relationship between waterpipe smoking and education level or socioeconomic status, other studies in different population groups demonstrated that religious inclination, parental smoking and low academic achievement are related to waterpipe smoking amongst young adults [16]. Third, widespread use of internet and social media platforms seems to make WPS increasingly fashionable and popular among young adults, and misconceived as a less harmful social activity than conventional cigarette use. Although originating in the Middle East, the internet and social media helped the spread of WPS across the world. Data show that internet searches for "waterpipe" have increased steadily since 2004 in Australia, Canada, the UK and the USA [10]. Finally, the lack of waterpipe specific policies and regulations in most parts of the world, assist marketing of WPS amongst youth and young adults.

\section{Toxicology}

The toxic compounds of waterpipe smoking are not well studied compared with those in cigarettes. Table 1 summarises the major toxic and hazardous compounds of waterpipe smoke, compared with cigarette smoking. Of note, the concentration and amount of these compounds may vary widely, based on the type of waterpipe, tobacco or charcoal used. Nicotine, tar, carbon monoxide (CO), polycyclic aromatic hydrocarbons (PAH) aldehydes, furanic compounds, phenolic compounds, heterocyclic compounds, ultrafine particles and inorganic compounds such as heavy metals, have all been identified in waterpipe smoke [7].

Nicotine is a main chemical present in all forms of tobacco and considered a major cause of tobacco dependence. Nicotine is present in different amounts according to the type of tobacco used in waterpipe smoking, ranging from $67-713 \mathrm{mg}$ of nicotine per head. In addition to nicotine, nicotine-free dry particulate matter (known as tar) is also present in waterpipe smoke and in a 10-200 fold higher concentration than in conventional cigarette smoke [4, 7, 24].

$\mathrm{CO}$ is another hazardous compound of tobacco smoke. Several reports showed increased risk of CO poisoning in waterpipe smoking [25]. One study showed increased CO levels, in addition to an increase in nicotine, cotinine and pro-inflammatory cytokines, immediately after a session of smoking [26]. Blood carboxyhaemoglobin levels were also increased after WPS, whether in active or passive smokers, and may reach a level of 3.9-4.5\%. SHIHADEH et al. [7] demonstrated that CO levels are elevated in both tobacco 
TABLE 1 Concentration and health effects of major hazardous and toxic compounds of waterpipe smoke compared with cigarettes

\begin{tabular}{|c|c|c|c|}
\hline Compound/toxin & Cigarette concentration & Waterpipe concentration & Health effect/risk \\
\hline Nicotine $\mathrm{mg}$ & $0.1-3$ & $>0.01-9.29$ & Tobacco dependence \\
\hline Tar mg & $1-27$ & $242-2350$ & CVD, COPD, lung cancer \\
\hline Carbon monoxide mg & $12-23$ & $5.7-367$ & CVD \\
\hline Polycyclic aromatic hydrocarbons ng & & & Lung, larynx and oral cavity cancer \\
\hline Naphthalene & 360.8 & $30-3860$ & \\
\hline Fluoranthene & 52.7 & $354-2380$ & \\
\hline Carbonylic compounds & & & COPD, lung and larynx cancer \\
\hline Formaldehyde $\mu \mathrm{g}$ & $20-100$ & $36-630$ & \\
\hline Acetaldehyde $\mu \mathrm{g}$ & $400-1400$ & $120-2520$ & \\
\hline Tobacco-specific nitrosamines ng & & & $\begin{array}{l}\text { Lung, larynx, oral cavity, oesophageal } \\
\text { and bladder cancer }\end{array}$ \\
\hline NNK & $80-770$ & Limit of detection - 46.4 & \\
\hline NAB & $120-3700$ & 34.3 & \\
\hline Heavy metals & & & Lung inflammation, COPD \\
\hline Lead ng & $34-85$ & $200-6870$ & \\
\hline Nickel ng & Not detected -600 & $300-900$ & \\
\hline
\end{tabular}

and tobacco-free waterpipe use. This finding was replicated in another study by BLANK et al. [27], which suggest that $\mathrm{CO}$ levels are related to the charcoal burning; thus, the absence of tobacco does not make the waterpipe smoking safe.

PAHs are a well-known organic pollutants associated with carcinogenesis of several cancers, including lung, colon and pancreatic cancers [28]. Although studies are limited, there is evidence for the presence of $\mathrm{PAH}$ in waterpipe smoke [24]. In addition, the concentrations of these compounds in waterpipe smoke exceed those in regular cigarette smoke.

Aerosolized heavy metals such as copper, zinc, lead and boron have also been shown to be present in waterpipe smoke [7]. These metals has been proved to cause lung inflammation and oxidative stress, and increase the risk for lung diseases such as COPD [29, 30].

Overall, these data suggest that WPS is at least as hazardous and toxic as cigarette smoking, if not more so. Despite this, waterpipe smokers are still often under the misconception that the harmful effects and exposure to toxins is reduced or even neutralised by the passage of the smoke through water.

\section{Health effects of WPS}

Health effects of WPS are well documented, and although high-quality studies are lacking, the biologic reasons for these consequences are plausible. Exposure to waterpipe smoking is likely to cause respiratory disease, cardiovascular disease and increase the risk of cancer.

\section{Pulmonary and respiratory complications}

WPS can cause a wide spectrum of symptoms and pulmonary complications. Short-term effects may develop after short use of smoking. Several studies have shown that even a single WPS session lasting 30 min results in decreases in forced expiratory flow and other pulmonary functions, along with increases in blood pressure, heart rate, respiratory rate and carboxyhaemoglobin levels [31, 32]. Respiratory symptoms develop after exposure to WPS. Cough, difficulty breathing and frequent colds among adolescents and adults has been reported [33-35]. WPS is associated with increased proportion of chronic bronchitis, COPD and emphysema. WPS increases the risk for chronic bronchitis even after smoking cessation [36]. WPS was proven to be associated with lung function abnormalities. In a systematic review and meta-analysis that included 1156 patients, RAAD et al. [37] found that WPS was associated with abnormal spirometry measurements, including reduced forced expiratory volume in $1 \mathrm{~s}\left(\mathrm{FEV}_{1}\right)$, forced vital capacity (FVC) and $\mathrm{FEV}_{1} / \mathrm{FVC}$ ratio as compared with nonsmokers, but without significant differences compared with cigarette smokers. These effects on pulmonary function tests are profound and similar to deep inspiration cigarette smoking. The effects of waterpipe smoking on pulmonary function tests are related to the intensity and duration of waterpipe use. Another cross-sectional study from China that 
included 1238 individuals showed that waterpipe smokers had a 10.61-fold risk of developing COPD; $70.7 \%$ of the Chinese waterpipe smokers had abnormal lung function [35].

Other pulmonary effects include increasing risk for tuberculosis [38, 39]. Several studies had demonstrated the association between WPS and lung cancer. In a meta-analysis that examined the risk of cancer in waterpipe smokers, the risk was increased by an odds ratio of 4.58 [40].

\section{Cardiovascular complications}

Both short-term and long-term cardiovascular effects of WPS have been reported. RezK-Hanna et al. [41] evaluated the short-term effects of WPS on heart rate, blood pressure and arterial stiffness, using carotid-femoral pulse wave velocity and the aortic augmentation index, in 48 waterpipe smokers. The study showed a significantly increased heart rate, mean brachial arterial pressure and acute arterial stiffness. These findings were similar to those seen in cigarette smokers. Even a short duration of WPS (15 min), increased heart rate and systolic and diastolic blood pressure [42]. These short-term effects may be attributed to nicotine-induced $\beta$-adrenergic stimulation [43].

Several studies have reported an association between waterpipe smoking and increased risk of cardiovascular disease. Most of these studies are from the Middle East and included small sample sizes. Thus, generalizability and application of the findings in regions where demographics may differ is uncertain. In a cross-sectional study conducted in the Golestan province in Iran, heavy waterpipe smoking among 4075 years old individuals was significantly associated with heart disease (OR 3.75, 95\% CI 1.52-9.22) [44]. Another retrospective study evaluated the association between waterpipe smoking and myocardial infarction (MI) in catheterised Lebanese patients [45]. Out of 7594 patients who underwent coronary artery catheterisation, $7.5 \%$ were waterpipe smokers. MI was significantly and independently associated with WPS (OR 1.329, 95\% CI 1.04-1.68). A lifetime exposure exceeding 40 waterpipe years was associated with a 3-fold increase in the risk of angiographically diagnosed coronary artery disease [46].

Little is known about waterpipe use and risk of stroke. In a case-control study [47]. multivariate regression analysis found that WPS was an independent risk factor for first-ever ischaemic stroke (OR 3.2, 95\% CI 1.7-6.1).

\section{Risk of malignancy}

The risk of malignancy in waterpipe smokers has not been evaluated in high-quality studies. This is in sharp contrast to the extensive high-quality longitudinal data linking cigarette smoking with increased cancer risk. In one systematic review and meta-analysis [40], which included 13 case-control studies, a positive association was found between waterpipe smoking and lung cancer (OR 4.58, CI 2.61-8.03) and oesophageal cancer (OR 3.63, 95\% CI 1.39-9.44). In another systematic review and meta-analysis by WAZIRY et al. [48] evaluating the effects of waterpipe smoking on health outcomes, an increased risk for several types of cancer was found: three studies demonstrated an increased risk of oesophageal cancer (OR 4.14, 95\% CI 0.93-18.46), six studies showed an increased risk of lung cancer (OR 2.12, 95\% CI 1.323.42), and three studies showed increased risk for oral cancer (OR 4.17, 95\% CI 2.53-6.89). Other studies with smaller cohorts have shown an increased risk for gastric carcinoma (OR 2.16, 95\% CI 0.72-6.47); bladder cancer (OR 1.25, 95\% CI 0.99, 1.57); prostate cancer (OR 7.00, 95\% CI 0.90, 56.90) and nasopharyngeal carcinoma (OR 0.49, 95\% CI 0.20, 1.23) [48]. Although these studies provide some evidence on the risk of malignancy in WPS, risk estimates are predominantly from Middle Eastern countries and compare waterpipe smokers to either nonsmokers or other tobacco smokers. Larger longitudinal studies are urgently required to better assess the risk of malignancy in waterpipe smokers.

\section{Other complications}

Other complications of waterpipe smoking have been reported in several studies. These include the risk of low birthweight, metabolic syndrome and altered mental health [48]. There is an increased risk of infectious disease transmission, such as influenza and herpes simplex virus, by sharing the mouthpiece between users [49]. Although some studies reported an increased risk of hepatitis C transmission [50], a meta-analysis of three studies concluded this is unlikely [48]. In addition, there have been some reports on increased risk of tuberculosis transmission [38, 39]. Although the systematic review and meta-analysis by AKL et al. [49] demonstrated an increased risk for periodontal disease, WAzIRY et al. [48] concluded that waterpipe smoking is not associated with periodontal disease, gastro-oesophageal reflux, infertility or increased mortality. 
There is a significant risk associated with second-hand exposure to waterpipe smoke. This was evident in the study by BENTur et al. [26], which demonstrated increased carboxyhaemoglobin levels in those passively exposed to second-hand waterpipe smoke.

Various other reported conditions may also be associated with waterpipe use, including vocal cord lesions, transmission of Aspergillus, newborn pulmonary complications, eosinophilic pneumonia, and more [4, 51-53].

\section{Addiction and smoking cessation}

Waterpipe smoking is addictive due to development of nicotine dependence and the use of other inhaled additives and harmful substances such as marijuana and alcohol. Users often show symptoms of nicotine withdrawal when they abstain from use [54]. A cross-sectional study conducted on 1490 adults who were current Egyptian waterpipe smokers, demonstrated that a quarter of participants self-reported addiction to waterpipe smoking [55]. Another study evaluated nicotine dependence symptoms across Lebanese youth waterpipe smokers [56]. Both the proportion of participants endorsing nicotine dependence symptoms and the average number of symptoms, increased with increasing waterpipe frequency. Findings support that both higher frequency and longer sessions of smoking were associated with increased risk of nicotine dependence symptoms.

Evidence suggests that in addition to addiction, waterpipe smokers have difficulty quitting. In a random sample of 268 waterpipe smokers, the majority of users (86.5\%) believed they could quit using waterpipe at any time. Despite this, $60 \%$ of the participants had been unsuccessful in their attempts to stop WPS in the preceding year [57].

Studies on waterpipe smoking cessation interventions remain sparse. Three studies evaluated both behavioural and pharmacological interventions (using Bupropion) for waterpipe smoking cessation [58]. Waterpipe smoking cessation rates were higher in the intervention groups in all three studies. In addition, one double-blind randomised controlled study conducted by Dogar et al. [59] tested the efficacy of varenicline in achieving abstinence from all tobacco use among waterpipe smokers. This study included two parallel groups with a total number of 510 waterpipe smokers randomised for either varenicline or placebo who were followed for a period of 25 weeks post-randomisation. Unfortunately, varenicline was not more effective than placebo in aiding cessation of tobacco use in long-term daily waterpipe smokers.

These studies support the need for further interventions, both at individual and community levels to decrease waterpipe use.

Legalisation and regulation of waterpipe

There is need for strong regulation of waterpipe products and enforcement of waterpipe smoking bans in enclosed spaces, similar to restrictions on cigarette smoking. There is a strong enough scientific basis to support effective national, state/provincial, and local regulation, without delay.

Few studies have explored the marketing and regulation of waterpipe smoking, which has increased in the last two decades [60]. In a review of the literature, HADDAD et al. [60] found that the majority of waterpipe smokers are not aware of its risks, and policies do not address waterpipe smoking. Although some countries do regulate waterpipe tobacco products, the majority of countries do not specifically address it, and very little effective implementation of regulations exists. In a global analysis of waterpipe smoking legislation, most countries do not address waterpipe tobacco smoking regulations, and categorise it as a generic tobacco product [61]. Only four countries had waterpipe smoke-free laws, which did not differ in practice from countries without laws, and without additional guidance. Most countries, instead, rely on generic tobacco definitions to cover all products. In addition, there is widespread noncompliance and lack of enforcement of smoking bans in countries such as India, Pakistan and the UK.

Tobacco companies tend to market waterpipe products using deceptive tactics suggesting waterpipe use is harmless. Marketing often targets young adults and adolescents, who may become lifelong smokers. Since 2016, the Food and Drug Administration has regulated the manufacturing, import, packaging, labelling, advertising, promotion, sale and distribution of waterpipe tobacco [62]. Although clean indoor air laws exist in many US states, waterpipe cafes are too often exempt.

In their review paper, KIENHUIS et al. [63] recommended including all waterpipe products in tobacco-product regulations and smoking bans in order to ban waterpipe molasses, mandate dissemination of information on all waterpipe tobacco elements to the national regulator, and prescribe testing to regulate contents of waterpipe smoking products and heating sources. In addition, the World Health 
Organization (WHO) recommends reinforcing the need for proper regulation and documentation of effective practices [64].

There are active regulatory actions that can be taken to reduce waterpipe smoking. These include clean indoor air in waterpipe cafes, increasing public awareness campaigns that address the adverse health consequences of waterpipe smoking and taxation of waterpipe tobacco products. Data support that these strategies are effective in reducing morbidity and mortality of waterpipe smoking [65].

\section{Future research}

Although waterpipe use has been present for several centuries, many aspects of this phenomenon remain poorly investigated. Nevertheless, the current available data suggests waterpipe is a major health hazard with substantial impact. There are several reasons for the lack of data and under-studied aspects. First, there are many different tobacco and nontobacco formulas being used in waterpipes, which contain different hazardous components. Second, different terms have been used in the literature to describe waterpipe use; these include waterpipe, shisha, goza, narghile, argilla, nafas and hookah. This has created confusion and lack of uniformity among studies. Third, there is no standardised method to quantify the use of waterpipe. Fourth, longitudinal studies investigating the long-term health effects of waterpipe are lacking.

Thus many aspects of waterpipe smoking require further research, as recommended by WHO [63], including but not limited to: the types and patterns of smoking across regions and countries, the pharmacology and toxicology in laboratory and in real-world use, the epidemiology of waterpipe smoking and associated risks of disease, and prevention and cessation strategies.

\section{Conclusion}

Waterpipe smoking has become a popular worldwide phenomenon, particularly among young individuals and there is growing evidence regarding its' dangerous health effects, including increased risk of respiratory symptoms, pulmonary function abnormalities, cardiovascular disease and malignancy. It is apparent that waterpipe smoking effects are at least similar to other tobacco forms, and pose a significant public health risk. Healthcare professionals should be encouraged to identify waterpipe smokers, educate them about potential harmful effects and monitor for the development of associated diseases. In addition, population-based approaches, such as applying WHO-FCTC (World Health Organization Framework Convention on Tobacco Control) regulations to waterpipe smoking and its tobacco products will have a synergistic effect and achieve higher impact in reducing waterpipe use and associated disease.

Provenance: Submitted article, peer reviewed

Conflict of interest: None declared.

\section{References}

1 Salloum RG, Thrasher JF, Kates FR, et al. Water pipe tobacco smoking in the United States: findings from the National Adult Tobacco Survey. Prev Med 2015; 71: 88-93.

2 Jamal A, Phillips E, Gentzke AS, et al. Current cigarette smoking among adults - United States, 2016. MMWR Morb Mortal Wkly Rep 2018; 67: 53-59.

3 National Center for Chronic Disease Prevention and Health Promotion (US) Office on Smoking and Health. The Health Consequences of Smoking - 50 Years of Progress a Report of the Surgeon General. Atlanta, Centers for Disease Control and Prevention (US), 2014.

4 Bou Fakhreddine HM, Kanj AN, Kanj NA. The growing epidemic of water pipe smoking: health effects and future needs. Respir Med 2014; 108: 1241-1253.

5 Patel MP, Khangoora VS, Marik PE. A review of the pulmonary and health impacts of hookah use. Ann Am Thorac Soc 2019; 16: 1215-1219.

6 Kandela P. Nargile smoking keeps Arabs in Wonderland. Lancet 2000; 356: 1175.

7 Shihadeh A, Schubert J, Klaiany J, et al. Toxicant content, physical properties and biological activity of waterpipe tobacco smoke and its tobacco-free alternatives. Tob Control 2015; 24: Suppl. 1, i22-i30.

8 Akl EA, Gunukula SK, Aleem S, et al. The prevalence of waterpipe tobacco smoking among the general and specific populations: a systematic review. BMC Public Health 2011; 11: 244.

9 Maziak W, Taleb ZB, Bahelah R, et al. The global epidemiology of waterpipe smoking. Tob Control 2015; 24: Suppl. 1, i3-i12.

10 Maziak W, Taleb ZB, Bahelah R, et al. The global epidemiology of waterpipe smoking. Tob Control 2015; 24: Suppl. 1, i3-i12. 
11 Jawad M, Charide R, Waziry R, et al. The prevalence and trends of waterpipe tobacco smoking: a systematic review. PLos One 2018; 13: e0192191.

12 Shihadeh A, Azar S, Antonios C, et al. Towards a topographical model of narghile water-pipe café smoking: a pilot study in a high socioeconomic status neighborhood of Beirut, Lebanon. Pharmacol Biochem Behav 2004; 79: 75-82.

13 Abdullah P, Costanian C, Khanlou N, et al. Prevalence and characteristics of water-pipe smoking in Canada: results from the Canadian Tobacco Use Monitoring Survey. Public Health 2017; 148: 102-108.

14 Pratiti R, Mukherjee D. Epidemiology and adverse consequences of hookah/waterpipe use: a systematic review. Cardiovasc Hematol Agents Med Chem 2019; 17: 82-93.

15 Jawad M, Wilson A, Lee JT, et al. Prevalence and predictors of water pipe and cigarette smoking among secondary school students in London. Nicotine Tob Res 2013; 15: 2069-2075.

16 Korn L, Magnezi R. Cigarette and nargila (water pipe) use among Israeli Arab high school students: prevalence and determinants of tobacco smoking. ScientificWorldJournal 2008; 8: 517-525.

17 Tageldin MA, Nafti S, Khan JA, et al. Distribution of COPD-related symptoms in the Middle East and North Africa: results of the BREATHE study. Respir Med 2012; 106: Suppl. 2, S25-S32.

18 Jawad M, Lee JT, Millett $C$. The relationship between waterpipe and cigarette smoking in low and middle income countries: cross-sectional analysis of the Global Adult Tobacco Survey. Plos One 2014; 9: e93097.

19 CDC. Global Tobacco Surveillance System Data. Atlanta, Centers for Disease Control and Prevention (US), 2019. www.cdc.gov/tobacco/global/gtss/gtssdata/index.html. Date last accessed: January 25, 2021

20 Ward KD, Eissenberg T, Rastam S, et al. The tobacco epidemic in Syria. Tob Control 2006; 15: 24-29.

21 Kasza KA, Ambrose BK, Conway KP, et al. Tobacco-product use by adults and youths in the United States in 2013 and 2014. N Engl J Med 2017; 376: 342-353.

22 Case KR, Creamer MLR, Cooper MR, et al. Hookah use as a predictor of other tobacco product use: a longitudinal analysis of Texas college students. Addict Behav 2018; 87: 131-137.

23 Sidani JE, Shensa A, Yabes J, et al. Waterpipe tobacco use in college and non-college young adults in the USA. Fam Pract 2019; 36: 103-109.

24 Sepetdjian E, Shihadeh A, Saliba NA. Measurement of 16 polycyclic aromatic hydrocarbons in narghile waterpipe tobacco smoke. Food Chem Toxicol 2008; 46: 1582-1590.

25 La Fauci G, Weiser G, Steiner IP, et al. Carbon monoxide poisoning in narghile (water pipe) tobacco smokers. Can J Emerg Med 2012; 14: 57-59.

26 Bentur L, Hellou E, Goldbart A, et al. Laboratory and clinical acute effects of active and passive indoor group water-pipe (narghile) smoking. Chest 2014; 145: 803-809.

27 Blank MD, Cobb CO, Kilgalen B, et al. Acute effects of waterpipe tobacco smoking: a double-blind, placebo-control study. Drug Alcohol Depend 2011; 116: 102-109.

28 Straif K, Baan R, Grosse Y, et al. Carcinogenicity of polycyclic aromatic hydrocarbons. Lancet Oncol 2005; 6: 931-932.

29 Khabour OF, Alzoubi KH, Bani-Ahmad M, et al. Acute exposure to waterpipe tobacco smoke induces changes in the oxidative and inflammatory markers in mouse lung. Inhal Toxicol 2012; 24: 667-675.

30 Wong J, Magun B, Wood L. Lung inflammation caused by inhaled toxicants: a review. Int J Chron Obstruct Pulmon Dis 2016; 11: 1391-1401.

31 Yalcin F, Er M, Hasanoglu HC, et al. Deteriorations of pulmonary function, elevated carbon monoxide levels and increased oxidative stress amongst water-pipe smokers. Int J Occup Med Environ Health 2017; 30: 731-742.

32 Hakim F, Hellou E, Goldbart A, et al. The acute effects of water-pipe smoking on the cardiorespiratory system. Chest 2011; 139: 775-781.

33 Rice VH, Templin TN, Harden JK, et al. Health effects reported by adolescent water pipe and/or cigarette smokers compared to nonsmokers. J Adolesc Heal 2019; 64: 333-339.

34 Boskabady M, Farhang L, Mahmoodinia M, et al. Prevalence of water pipe smoking in the city of Mashhad (North East of Iran) and its effect on respiratory symptoms and pulmonary function tests. Lung India 2014; 31: 237-243.

35 She J, Yang P, Wang Y, et al. Chinese water-pipe smoking and the risk of COPD. Chest 2014; 146: 924-931.

36 Salameh P, Waked M, Khoury F, et al. Waterpipe smoking and dependence are associated with chronic bronchitis: a case-control study in Lebanon. East Mediterr Health J 2012; 18: 996-1004.

37 Raad D, Gaddam S, Schunemann HJ, et al. Effects of water-pipe smoking on lung function: a systematic review and meta-analysis. Chest 2011; 139: 764-774.

38 Munckhof WJ, Konstantinos A, Wamsley M, et al. A cluster of tuberculosis associated with use of a marijuana water pipe. Int J Tuberc Lung Dis 2003; 7: 860-865.

39 Steentoft J, Wittendorf J, Andersen JR. Tuberculosis and water pipes as source of infection in Storstroem County, Denmark. Ugeskr Laeger 2006; 168: 904-907.

40 Montazeri Z, Nyiraneza C, El-Katerji H, et al. Waterpipe smoking and cancer: systematic review and meta-analysis. Tob Control 2017; 26: 92-97. 
41 Rezk-Hanna M, Doering L, Robbins W, et al. Acute effect of hookah smoking on arterial stiffness and wave reflections in adults aged 18 to 34 years of age. Am J Cardiol 2018; 122: 905-909.

42 Azar RR, Frangieh AH, Mroué J, et al. Acute effects of waterpipe smoking on blood pressure and heart rate: a real-life trial. Inhal Toxicol 2016; 28: 339-342.

43 Blank MD, Cobb CO, Kilgalen B, et al. Acute effects of waterpipe tobacco smoking: a double-blind, placebo-control study. Drug Alcohol Depend 2011; 116: 102-109.

44 Islami F, Pourshams A, Vedanthan R, et al. Smoking water-pipe, chewing nass and prevalence of heart disease: a cross-sectional analysis of baseline data from the Golestan Cohort Study, Iran. Heart 2013; 99: 272-278.

45 Platt DE, Hariri E, Salameh P, et al. Association of waterpipe smoking with myocardial infarction and determinants of metabolic syndrome among catheterized patients. Inhal Toxicol 2017; 29: 429-434.

46 Sibai AM, Tohme RA, Almedawar MM, et al. Lifetime cumulative exposure to waterpipe smoking is associated with coronary artery disease. Atherosclerosis 2014; 234: 454-460.

47 Tabrizi R, Borhani-Haghighi A, Lankarani KB, et al. Hookah smoking: a potentially risk factor for first-ever ischemic stroke. J Stroke Cerebrovasc Dis 2020; 29: 105138.

48 Waziry R, Jawad M, Ballout RA, et al. The effects of waterpipe tobacco smoking on health outcomes: an updated systematic review and meta-analysis. Int J Epidemiol 2017; 46: 32-43.

49 Akl EA, Gaddam S, Gunukula SK, et al. The effects of waterpipe tobacco smoking on health outcomes: a systematic review. Int J Epidemiol 2010; 39: 834-857.

50 Habib M, Mohamed MK, Abdel-Aziz F, et al. Hepatitis C virus infection in a community in the Nile Delta: risk factors for seropositivity. Hepatology 2001; 33: 248-253.

51 Lim BL, Lim GH, Seow E. Case of carbon monoxide poisoning after smoking shisha. Int J Emerg Med 2009; 2: 121-122.

52 Dyal H, Singhvi A, Patel R, et al. A case of eosinophilic pneumonia following recent onset of hookah smoking. Chest 2014; 146: 406A.

53 De Dios JAA, Javaid AA, Mesologites T, et al. A 20-year-old man with fever, chest pain, and lung nodules. Chest 2011; 140: 1378-1381.

54 Aboaziza E, Eissenberg T. Waterpipe tobacco smoking: what is the evidence that it supports nicotine/tobacco dependence? Tob Control 2015; 24: Suppl. 1, i44-i53.

55 Mostafa A. Self-reported addiction to and perceived behavioural control of waterpipe tobacco smoking and its patterns in Egypt: policy implications. East Mediterr Health J 2020; 26: 18-28.

56 Bahelah R, DiFranza JR, Ward KD, et al. Waterpipe smoking patterns and symptoms of nicotine dependence: the Waterpipe Dependence in Lebanese Youth Study. Addict Behav 2017; 74: 127-133.

57 Ward KD, Hammal F, VanderWeg MW, et al. Are waterpipe users interested in quitting? Nicotine Tob Res 2005; 7: 149-156.

58 Maziak W, Jawad M, Jawad S, et al. Interventions for waterpipe smoking cessation. Cochrane Database Syst Rev 2015; 7: CD0005549.

59 Dogar O, Zahid R, Mansoor S, et al. Varenicline versus placebo for waterpipe smoking cessation: a double-blind randomized controlled trial. Addiction 2018; 113: 2290-2299.

60 Haddad L, El-Shahawy O, Ghadban R, et al. Waterpipe smoking and regulation in the United States: a comprehensive review of the literature. Int J Environ Res Public Health 2004; 12: 6115-6135.

61 Jawad M, Kadi LE, Mugharbil S, et al. Waterpipe tobacco smoking legislation and policy enactment: a global analysis. Top Control 2015; 24: Suppl. 1, i60-i65.

62 FDA. Hookah tobacco (shisha or waterpipe tobacco). Silver Spring, U.S. Food \& Drug Administration, 2020. www.fda.gov/tobacco-products/products-ingredients-components/hookah-tobacco-shisha-or-waterpipe-tobacco. Date last accessed: January 5, 2021

63 Kienhuis AS, Talhout R. Options for waterpipe product regulation: a systematic review on product characteristics that affect attractiveness, addictiveness and toxicity of waterpipe use. Tob Induc Dis 2020; 18: 69.

64 WHO. Advisory note: waterpipe tobacco smoking: health effects, research needs and recommended actions for regulators - 2nd edition. Geneva, World Health Organization, 2015. www.who.int/tobacco/publications/ prod_regulation/waterpipesecondedition/en/. Date last accessed: November 11, 2020.

65 Leavens EL, Driskill LM, Molina N, et al. Comparison of a preferred versus non-preferred waterpipe tobacco flavour: subjective experience, smoking behaviour and toxicant exposure. Tob Control 2018; 27: 319-324. 